\title{
Chemical Composition and Biological Activities of Artemisia pedemontana subsp. assoana Essential Oils and Hydrolate
}

\author{
Paula Sainz ${ }^{1,2}$, María Fe Andrés ${ }^{1}$, , Rafael A. Martínez-Díaz ${ }^{2}$, María Bailén ${ }^{3}$, \\ Juliana Navarro-Rocha ${ }^{4}$, Carmen E. Díaz ${ }^{5}$ and Azucena González-Coloma ${ }^{1} *$ (D) \\ 1 Instituto de Ciencias Agrarias, Consejo Superior de Investigaciones Científicas, 28006 Madrid, Spain; \\ paula.sainz.sotomayor@gmail.com (P.S.); mafay@ica.csic.es (M.F.A.) \\ 2 Departamento de Medicina Preventiva, Salud Pública y Microbiología, Facultad de Medicina, Universidad \\ Autónoma de Madrid, 28029 Madrid, Spain; rafael.martinez@uam.es \\ 3 Departamento de Farmacia y Biotecnología, Facultad de Ciencias, Universidad Europea de Madrid, \\ 28670 Villaviciosa de Odón, Madrid, Spain; maria.bailen@universidadeuropea.es \\ 4 Centro de Investigación y Tecnología Agroalimentaria de Aragón, Unidad de Recursos Forestales, \\ 50059 Zaragoza, Spain; jnavarroro@aragon.es \\ 5 Instituto de Productos Naturales y Agrobiología, Consejo Superior de Investigaciones Científicas, \\ 38206 La Laguna, Tenerife, Spain; celisa@ipna.csic.es \\ * Correspondence: azu@ica.csic.es
}

Received: 5 August 2019; Accepted: 27 September 2019; Published: 2 October 2019

\begin{abstract}
Given the importance of the genus Artemisia as a source of valuable natural products, the rare plant Artemisia pedemontana subspecies assoana, endemic to the Iberian Peninsula, has been experimentally cultivated in the greenhouse and aeroponically, to produce biomass for essential oil (EO) extraction. The chemical composition of the EOs was analyzed, and their plant protection (insects: Spodoptera littoralis, Rhopalosiphum padi, and Myzus persicae; plants: Lactuca sativa and Lolium perenne; fungi: Aspergillus niger; and nematode: Meloidogyne javanica) and antiparasitic (Trypanosoma cruzi, Phytomonas davidi, and antiplasmodial by the ferriprotoporphyrin biocrystallization inhibition test) properties were studied, in addition to the hydrolate by-product. The EOs showed a 1,8-cineole and camphor profile, with quantitative and qualitative chemical differences between the cultivation methods. These oils had moderate insect antifeedant, antifungal, and phytotoxic effects; were trypanocidel; and exhibited moderate phytomonacidal effects, while the hydrolate showed a strong nematicidal activity. Both EOs were similarly antifeedant; the EO from the greenhouse plants (flowering stage) was more biocidal (antifungal, nematicidal, and phytotoxic) than the EO from the aeroponic plants (growing stage), which was more antiparasitic. The major components of the oils (1,8-cineole and camphor), or their 1:1 combination, did not explain any of these effects. We can conclude that these EOs have potential applications as insect antifeedants, and as antifungal or antiparasitic agents, depending on the cultivation method, and that the hydrolate byproduct is a potent nematicidal.
\end{abstract}

Keywords: Artemisia pedemontana subspecies assoana; experimental cultivation; essential oil; hydrolate; antitrypanosomal; phytomonacidal; antiplasmodial; insect antifeedant; phytotoxic; antifungal; nematicidal

\section{Introduction}

The genus Artemisia (Asteraceae family) has been widely studied from a phytochemical point of view. Artemisia species produce essential oils [1] and have a broad spectrum of bioactivity, including antibacterial [2,3], antiviral [4], antiparasitic [5-9], antifungal [10], nematicidal [11], and insecticidal [12,13], 
and overall, contribute a great deal to the plant defensive properties. However, some species have been poorly studied, mostly because of their lack of abundance or distribution [14]. One of such species is Artemisia pedemontana (Bent), a whitish-lanate perennial aromatic shrub with a circummediterranean disjunct distribution [15]. In the Iberian Peninsula, the endemic subspecies A. pedemontana subsp. assoana (Willk.) Rivas Mart. grows in disturbed grazed land in a continental climate at 900-2000 m [16].

This plant subspecies has been subjected to a few phytochemical studies. There is one report on the essential oil composition of wild A. pedemontana subsp. assoana from two populations [17]. Additionally, two sesquiterpene lactones have been identified from organic extracts of its aerial parts [18], while the roots yielded flavones, coumarins, diacetylenic spiroketal enolethers, and n-akyl p-coumarates [19]. There are no additional studies on the bioactivity (pharmacological or other) of $A$. pedemontana subsp. assoana extracts or components.

As part of an ongoing valorization of rare species from the genus Artemisia from the Iberian Peninsula, this work studied the essential oil composition of experimentally cultivated A. pedemontana subsp. assoana (in a greenhouse without environmental control, and in an aeroponic system with a controlled environment).

Given the importance of Artemisia species as a source of antiparasitic and biocidal agents [14], the antiparasitic effects of these essential oils were tested against epimastigotes of Trypanosoma cruzi, the etiologic agent of the Chagas disease, and promastigotes of Phytomonas davidi, a plant trypanosomatid that causes several diseases in crops of great importance [20]. The antimalarial potential of these oils was tested in vitro using the ferriprotoporphyrin (FP) IX biocrystallization inhibition [21,22]. The plant protection effects included insect antifeedant (Spodoptera littoralis, Myzus persicae and Rhopalosiphum padi), antifungal (Aspergillus niger), phytotoxic (Lactuca sativa and Lolium perenne), and nematicidal (Meloidogyne javanica) activities.

\section{Materials and Methods}

\subsection{Plant Material and Cultivation}

A. pedemontana subsp. assoana seeds were collected from a wild population (Campillo de Aragón, Spain, GPS coordinates $41^{\circ} 06^{\prime} 31.7^{\prime \prime} \mathrm{N} 1^{\circ} 50^{\prime} 39.7^{\prime \prime} \mathrm{W}, 1050 \mathrm{~m}$ of altitude) and germinated in a growth chamber $\left(25^{\circ} \mathrm{C}, 70 \% \mathrm{RH}\right.$ with a photoperiod of $16: 8 \mathrm{~h}$ (light (L):dark(D)).

The seedlings were grown in a substrate composed of three parts of sand and one of peat, and were cultivated in a greenhouse without environmental control. A selected plant was used for the vegetative reproduction, and these plants were used in the aeroponic and greenhouse experimental cultivation. Plants of 10-15 cm height, kept in a growth chamber at the environmental conditions described above, were transferred to an aeroponic chamber (Apollo 3 system: 33 plants, $240 \mathrm{~L}, 1750 \mathrm{~mm}$ $\times 1350 \mathrm{~mm} \times 750 \mathrm{~mm})$ located in a growth chamber $\left(25^{\circ} \mathrm{C}, 70 \% \mathrm{RH}\right.$ with a photoperiod of 16:8 h (L:D). The plants were pulverized for 15 min every $2 \mathrm{~h}$ with water supplemented with $0.2 \mathrm{~g} / \mathrm{L}$ Nutrichem (20:20:20 of N:P:K-Miller Chemical and Fertilizer Crop, Hanover, PA, USA) and $0.03 \% \mathrm{H}_{2} \mathrm{O}_{2}(33 \%$ $w / v$ Panreac Química SLU, Castellar del Vallès, Barcelona, Spain).

The plant aerial parts were collected at the flowering stage from the greenhouse, and periodically, 20-30 cm plants were selected from the aeroponic chamber at growing stage, dried $\left(26{ }^{\circ} \mathrm{C}\right.$ for five days in an air-forced ventilated stove), and grounded prior to extraction.

\subsection{Essential Oil Extraction}

Hydrodistillation was performed using a Clevenger-type apparatus with an extraction chamber, separated according to the method recommended by the European Pharmacopoeia (http://www.edqm. eu/en/Homepage-628.html). Each extraction was carried out in triplicate with $100 \mathrm{~g}$ of dried aerial plant parts for $2 \mathrm{~h}$. The hydrolate (aqueous phase) was decanted from the essential oil collected in the condensation section of the Clevenger, and was filtered. The total volumes obtained were 2.1 and $1.2 \mathrm{~mL}$ of greenhouse and aeroponic EO (0.7\% and $0.4 \%$ yield, respectively) and $20 \mathrm{~mL}$ of hydrolate. The EOs were dried over anhydrous sodium sulfate and stored at $4-6{ }^{\circ} \mathrm{C}$ until the chemical analysis. 


\subsection{Gas Chromatography-Mass Spectrometry Analysis}

The essential oils were analyzed by gas chromatography-mass spectrometry (GC-MS) using a Shimadzu GC-2010 gas chromatograph coupled to a Shimadzu GCMS-QP2010 Ultra mass detector (electron ionization, $70 \mathrm{eV}$, Duisburg, Germany) and equipped with a $30 \mathrm{~m} \times 0.25 \mathrm{~mm}$ i.d. capillary column (0.25 $\mu \mathrm{m}$ film thickness) Teknokroma TRB-5 (95\%) dimethyl-(5\%) diphenylpolisiloxane. The working conditions were as follows: split ratio (20:1), injector temperature $300{ }^{\circ} \mathrm{C}$, temperature of the transfer line connecter to the mass spectrometer $250{ }^{\circ} \mathrm{C}$, initial column temperature $70^{\circ} \mathrm{C}$, then heated to $290{ }^{\circ} \mathrm{C}$ at $6^{\circ} \mathrm{C} / \mathrm{min}$. Electron ionization mass spectra and retention data were used to assess the identity of the compounds by comparing them with those of the standards or those found in the Wiley 229 Mass Spectral Database. The relative amounts of individual components were calculated based on the GC peak area (flame ionization Detector, FID, response), without using a correction factor. The relative standard deviation (calculated as SD/average $\times 100$ ) for the \% peak area (three injections/sample) was $\leq 1 \%$. Electron ionization mass spectra and retention data were used to assess the identity of the compounds by comparing them with those found in the Wiley 229 Mass Spectral Database.

\subsection{Antiparasite Bioassays}

The human parasite Trypanosoma cruzi Y-strain, and the plant parasite Phytomonas davidi ATCC ${ }^{\circledR}$ 30287TM strain, were used to test antiparasitic effects on the epimastigote and promastigote forms, respectively. T. cruzi epimastigotes and P. davidi promastigotes were grown axenically at $28{ }^{\circ} \mathrm{C}$ in liver infusion tryptose (LIT) supplemented with 10\% heat-inactivated fetal calf serum (FCS; Gibco, Dublin, Ireland).

\subsubsection{Trypanosoma cruzi Susceptibility Assay}

The activity on the epimastigote forms of T. cruzi was evaluated on cultures in a LIT medium supplemented with $10 \%$ heat-inactivated (FCS). The parasites in the logarithmic growth phase $\left(8-10 \times 10^{6}\right.$ epimastigote/mL) were distributed in 96-well flat-bottom plates (90 $\mu \mathrm{L}$ of culture/well). Essential oils and compounds (1,8-cineole and camphor from Sigma-Aldrich Quimica SL, Madrid, Spain) were tested in triplicate at several concentrations (EOs at 800, 400, 200, and $100 \mu \mathrm{g} / \mathrm{mL}$; compounds at 100, 10, and $1 \mu \mathrm{g} / \mathrm{mL}$ ) for $72 \mathrm{~h}$. Nifurtimox (Bayer AG, Monheim am Rhein, Germany) was used as the positive control, and the parasite viability was analyzed by a modified 3-(4,5-dimethylthiazol-2-yl)-2,5-diphenyltetrazolium bromide (MTT) colorimetric assay method [7]. Data were analyzed with Statgraphics statistical analysis software (Centurion XVIII, Statgraphics Technologies, Inc., The Plains, VA, USA) using one-way analysis of variance (ANOVA) and least significant difference (LSD) test $(p<0.05)$ analyses.

\subsubsection{Phytomonas davidi Susceptibility Assay}

A new bioassay has been developed to evaluate the activity of the EOs against promastigote forms of $P$. davidi, cultured in a LIT medium supplemented with $10 \%$ heat-inactivated (FCS). Parasites in the logarithmic growth phase $\left(5 \times 10^{4}\right.$ promastigotes $\left./ \mathrm{mL}\right)$ were distributed in 96 -well flat-bottom plates $(90 \mu \mathrm{L}$ of culture/well). The essential oils and compounds were tested in triplicate at several concentrations (EOs at 800, 400, 200 and $100 \mu \mathrm{g} / \mathrm{mL}$; compounds at 100, 10 and $1 \mu \mathrm{g} / \mathrm{mL}$ ) for $24 \mathrm{~h}$. The parasite viability was analyzed by a modified MTT colorimetric assay method using Menadione instead of phenazine methosulfate (PMS) as the electron-coupling agent. Briefly, after $24 \mathrm{~h}, 10 \mu \mathrm{L}$ of the solution of $15 \mathrm{mg}$ of MTT, and $0.5 \mathrm{mg}$ Menadione in $3 \mathrm{~mL}$ PBS were added to each well. This was incubated for $75 \mathrm{~min}$ for the reduction of MTT to occur, and $100 \mu \mathrm{L}$ sodium dodecyl sulphate was added to dissolve the formazan crystals obtained as a result of the reduction of MTT. The absorbance was read on a spectrophotometer at $603 \mathrm{~nm}$. The activity was calculated as in the epimastigote assay, and submitted to the same statistical analysis described before. 


\subsubsection{Ferriprotoporphyrin (FP) IX Biocrystallization Inhibition Test (FBIT)}

This bioassay was performed to evaluate the inhibition of FP biocrystallization in presence of the essential oils and the pure compounds [22]. The bioassay was carried out in a non-sterile 96-well plate flat-bottom at $37^{\circ} \mathrm{C}$ for $18-24 \mathrm{~h}$. The EOs and pure compounds were tested at several concentrations (EOs at 10,5, and $2.5 \mathrm{mg} / \mathrm{mL}$; and compounds at 100, 50, and $25 \mu \mathrm{g} / \mathrm{mL}$ ). Chloroquine biphosphate (Sigma-Aldrich) was used as the reference drug. A series of solutions were added to the plate, namely: $0.5 \mathrm{mg} / \mathrm{mL}$ of hemin chloride (Sigma-Aldrich) freshly dissolved in dimethylsulphoxide (DMSO) (50 $\mu \mathrm{L})$, $100 \mu \mathrm{L}$ of $0.5 \mathrm{M}$ sodium acetate buffer ( $\mathrm{pH} 4.4$ ), and $50 \mu \mathrm{L}$ of EOs or compounds dissolved in DMSO. After 18-24 h, the plates were centrifuged at $3000 \mathrm{rpm}$ for $5 \mathrm{~min}$, and the supernatant was discarded. The remaining pellet was resuspended in $200 \mu \mathrm{L}$ of DMSO so as to remove the unreacted FP. The plate was centrifuged again and the supernatant was discarded. The pellet was dissolved in $150 \mu \mathrm{L}$ of $0.1 \mathrm{M} \mathrm{NaOH}$, and the absorbance measured at $405 \mathrm{~nm}$. The percentage of inhibition of the FP biocrystallization was calculated as follows:

$$
\text { Inhibition }(\%)=100 \times[(\mathrm{OD} \text { control }-\mathrm{OD} \text { treatment }) / \mathrm{OD} \text { control }]
$$

\subsection{Insect Bioassays}

Spodoptera littoralis, Myzus persicae, and Rhopalosiphum padi colonies were reared on an artificial diet [23], bell pepper (Capsicum annuum), and barley (Hordeum vulgare) plants, respectively, and maintained at $22 \pm 1^{\circ} \mathrm{C},>70 \%$ relative humidity with a photoperiod of 16:8 h(L:D) in a growth chamber.

The bioassays were conducted with newly emerged $S$. littoralis L6 larvae (2/plate, 10 plates) or M. persicae/R. padi adults (10/box, 20 boxes). The feeding or settling inhibition (\%FI or \%SI) were calculated as $\% \mathrm{FI}=[1-(\mathrm{T} / \mathrm{C})] \times 100$, where $\mathrm{T}$ and $\mathrm{C}$ are the consumption of the treated and control leaf disks, respectively, or as $\% \mathrm{SI}=[1-(\% \mathrm{~T} / \% \mathrm{C})] \times 100$, where $\% \mathrm{C}$ and $\% \mathrm{~T}$ are the percentage of aphids settled on the control and treated leaf disks, respectively [24]. The antifeedant effects (\%FI/\%SI) were analyzed for significance by the non-parametric Wilcoxon signed rank test. The $\mathrm{EC}_{50}$ values (effective dose to obtain $50 \%$ feeding inhibition) were determined for the EOs and pure compounds with $\% \mathrm{FI} / \% \mathrm{SI}$ values $>70 \%$ from a linear regression analysis (Statgraphics statistical analysis software).

\subsection{Phytotoxic Activity}

The experiments were conducted with Lactuca sativa cv. Teresa (Fitó, Selva de Mar, Barcelona, Spain), and Lolium perenne (Batlle, Molins de Rei, Barcelona, Spain) seeds, as described [25]. Briefly, $2.5 \mathrm{~cm}$ diameter filter paper with $20 \mu \mathrm{L}$ of the test solution $(10 \mu \mathrm{g} / \mu \mathrm{L}$ for EOs, $5 \mu \mathrm{g} / \mu \mathrm{L}$ for pure compounds) were placed on 12-well plates (Falcon, Corning, NY, USA) and then $500 \mu \mathrm{L} \mathrm{H}_{2} \mathrm{O} /$ well and 10/5 seeds (L. sativa/L. perenne pre-soaked in distilled water for $12 \mathrm{~h}$ ) were added. The covered plates were placed in a plant growth chamber $\left(25^{\circ} \mathrm{C}, 70 \% \mathrm{RH}, 16: 8 \mathrm{~L}: \mathrm{D}\right)$, and the germination was monitored for six days. At the end of the experiment, the root/leaf length was measured (25 plantlets randomly selected for each experiment and digitalized with the application ImageJ 1.43 (http://imagej.nih.gov/ij/)).

\subsection{Antifungal Bioassays}

The essential oils and the major compounds were tested against Aspergillus niger (donated by Dr. K. Leiss, Wageningen University). The antifungal activity was measured by an MTT colorimetric spore germination inhibition test [26]. Afterwards, the subculture from the potato dextrose agar (PDA) plates' conidial suspensions were prepared. For susceptibility testing, $1.5 \times 10^{4}$ conidia per well (counted in a Neubauer chamber) were seeded into flat-bottom 96-well plates in $200 \mu \mathrm{L}$ of morpholine-propanesulfonic acid (MOPS)-buffered RPMI medium (Sigma Aldrich). The plates were incubated for $24 \mathrm{~h}$ at $30^{\circ} \mathrm{C}$. Amphotericin B $(5 \mu \mathrm{g} / \mathrm{mL})$ was used as a positive control and DMSO $(1 \%)$ as a negative control (solvent and drug free control). After incubation, the spore germination was measured by a colorimetric method using the dye MTT. The medium (RPMI, $25 \mu \mathrm{L}$ ) with $5 \mathrm{mg} / \mathrm{mL}$ of 
MTT and menadione $1 \mathrm{mM}$ was added to each well and incubated at $37^{\circ} \mathrm{C}$ for $3 \mathrm{~h}$. The content of each well was removed, and $200 \mu \mathrm{L}$ of isopropanol with $5 \%$ of $\mathrm{HCl}(1 \mathrm{M})$ were added to each well to extract the dye. After $30 \mathrm{~min}$ of incubation at room temperature and gentle agitation, the optical density (OD) was measured at $490 \mathrm{~nm}$. Data were analyzed with Statgraphics statistical analysis software (Centurion XVIII) using ANOVA and least significant difference (LSD) test $(p<0.05)$ analysis.

\subsection{Nematicidal Bioassays}

A field-selected Meloidogyne javanica population from Barcelona, Spain, was maintained on tomato plants (Solanum lycopersicum L. var. Marmande) in pot cultures at $25 \pm 1{ }^{\circ} \mathrm{C},>70 \%$ relative humidity. The egg masses of M. javanica were handpicked from infected tomato roots two months after the inoculation of the seedlings. Second-stage juveniles (J2) were obtained by incubating the egg masses in a water suspension at $25^{\circ} \mathrm{C}$ for $24 \mathrm{~h}$.

\subsubsection{In Vitro Effect on Juveniles}

The experiments were carried out in 96-well microplates, as described previously [11]. The EOs were tested at an initial concentration of $1 \mathrm{mg} / \mathrm{mL}$ in DMSO-Tween $(0.5 \%$ Tween20 in DMSO), and the hydrolate was tested without dilution (100\%). Serial dilutions (1:2) were carried out when needed. All of the treatments were replicated four times, and the number of dead juveniles was recorded after $72 \mathrm{~h}$. The data were determined as percentage of mortality, corrected according to Scheider-Orelli's formula. The data were analyzed using ANOVA and least significant difference (LSD) test $(p<0.05)$ analysis. Effective lethal doses $\left(\mathrm{LC}_{50}\right)$ were calculated by Probit analysis (Statgraphics statistical analysis software, Centurion XVIII).

\subsubsection{In Vitro Effect on Egg Hatching}

Three egg masses of uniform size were washed with sterilized distilled water and transferred to a 24-well plate containing $400 \mu \mathrm{L}$ of the hydrolate (HAasA). The egg masses in the sterilized distilled water were used as the controls. Each experiment was replicated four times. The plates were covered to prevent evaporation, and were incubated in the darkness at $25{ }^{\circ} \mathrm{C}$. After five days, the hatched $\mathrm{J} 2 \mathrm{~s}$ were counted and the test solutions were replaced with sterilized distilled water. The egg masses were monitored for four weeks at weekly intervals, until hatching was complete in the control [11]. The relative hatch suppression rate (compared with the controls) was calculated.

\subsubsection{Effect on Juvenile Infection Capacity}

Three-week-old tomato seedlings (susceptible variety, Marmande, France) were transplanted into 5-cm-diameter clay pots filled with $10 \mathrm{~mL}$ of quartz sand. The seedlings were individually inoculated with 180-200 J2 untreated (control), or treated with hydrolate (HAasA) at a sublethal dose (LC 50$)$, and were incubated for one week in a growth chamber $\left(25 \pm 2{ }^{\circ} \mathrm{C}, 60 \% \mathrm{RH}\right.$, and 16:8 L:D). The seedlings were then removed and the roots were stained with acid fuchsine [11]. Juveniles within the roots of each individual seedling were counted by examining the entire root system under a stereomicroscope. The experiment consisted of six replicas, and was repeated two times. The relative percentages of the J2 penetration (treated vs. untreated) were calculated in order to obtain inhibition rates of J2 infectivity [11]. The Chi-square test was used to calculate the statistically significant difference between the proportions of the control juveniles (untreated) and treated juveniles that penetrated the tomato roots (Statgraphics statistical analysis software, Centurion XVIII).

\section{Results and Discussion}

\subsection{Biomass Production and Essential Oil (EO) Composition}

Two cultivation methods were used for the biomass production of $A$. pedemontana subsp. Assoana, namely: greenhouse and aeroponic systems. The greenhouse plants (AasG) grown without 
environmental control were morphologically similar to plants from wild populations (shorter and thicker), and flowered after the winter vegetative stage, while the aeroponic plants (AasA), grown with environmental control, remained in the growing stage, did not flower, and grew faster (Figure 1).

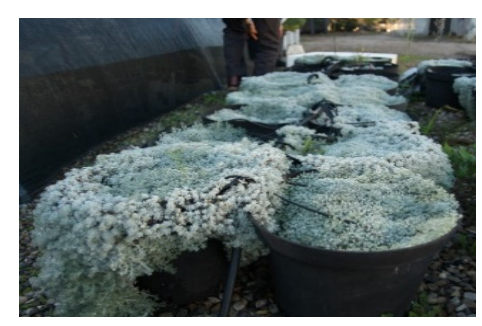

(a)

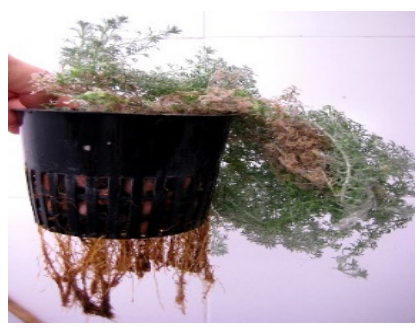

(b)

Figure 1. Artemisia pedemontana subsp. assoana pictures from both cultivation methods, namely: (a) plants growing in a greenhouse (AasG); (b) plant growing in an aeroponic system (AsA).

The essential oils (EOs) from the greenhouse and aeroponically cultivated A. pedemontana subsp. assoana yielded $0.7 \%$ and $0.4 \%$ (plant dry weight), respectively. The phenology of the samples (greenhouse in flowering stage and aeroponic in growing stage) could explain the difference in essential oil yield.

Table 1 shows the chemical composition of the essential oils. The major components were 1,8-cineole (22.8-25.8\%) and camphor (32.4-44.0\%). Quantitative differences were observed between the essential oils from the greenhouse and aeroponic plants. The monoterpene camphor was more abundant in the greenhouse population (AasG), while 1,8-cineole was more abundant in the oil from the aeroponic plants (AasA). Terpinen-4-ol (8.8\%) was the third major component of the AasG EO, followed by borneol (4.8\%), 1- $\alpha$-terpineol (3.6\%), and camphene (1.8\%), while the AasA EO had p-cymene (7.4\%), terpinen-4-ol (5.8\%), camphene (5.3\%), and borneol (2.8\%) as the main components.

There is only one report describing the chemical composition of the essential oils of two populations of $A$. pedemonana subsp. assoana. The authors suggested two different chemotypes, camphor and 1,8-cineole, and davanone [17]. Our results agree with the first chemotype (camphor and 1,8-cineole). Both monoterpenes are very common in the chemical composition of Artemisia sp. essential oils. Species like $A$. annua, $A$. fragans, $A$. longifolia, and $A$. ludoviciana are also rich in these two monoterpenes [1].

The qualitative differences between these oils included $\alpha$-terpinene $(0.9 \%), \gamma$-terpiene $(1.7 \%)$, sabinene $(2.5 \%)$, and sabinene isomer (1.5\%), only present in AasA; and linalool (1.6\%), bornyl acetate $(0.9 \%)$, and nerolidol $(0.8 \%)$, only found in the AasG EO.

Table 1. Chemical composition of the essential oil (EO) from cultivated Artemisia pedemontana subsp. assoana (greenhouse-AasG; aeroponic-AasA).

\begin{tabular}{cccc}
\hline Compounds & Rt $^{\mathbf{a}}$ & AasG & AasA \\
\hline$\alpha$-pinene & 3.94 & $0.54^{\mathrm{b}}$ & $0.89^{\mathrm{b}}$ \\
Camphene & 4.16 & 1.77 & 5.34 \\
$\beta$-pinene & 4.56 & 0.22 & 0.71 \\
$\alpha$-Terpinene & 5.15 & - & 0.99 \\
p-Cymene & 5.29 & 1.75 & 7.4 \\
1,8-Cineole & 5.43 & 22.88 & 25.78 \\
$\gamma$-Terpinene & 5.92 & - & 1.73 \\
Sabinene & 6.07 & - & 2.53 \\
Linalool & 6.66 & 1.56 & - \\
Sabinene Isomer & 6.68 & - & 1.45 \\
Camphor & 7.69 & 44.03 & 32.4 \\
Borneol & 8.12 & 4.79 & 2.77 \\
Terpinen-4-ol & 8.36 & 8.86 & 5.77 \\
\hline
\end{tabular}


Table 1. Cont.

\begin{tabular}{cccc}
\hline Compounds & $\mathbf{R t}^{\mathbf{a}}$ & AasG & AasA \\
\hline 1- $\alpha$-Terpineol & 8.64 & 3.6 & 1.6 \\
Bornyl acetate & 10.77 & 0.98 & - \\
Methyl eugenol & 13.34 & 1.27 & 1.82 \\
Nerolidol & 16.78 & 0.82 & - \\
Spathulenol & 17.19 & 1.03 & 0.59 \\
Viridiflorol & 17.51 & 1.69 & 1.59 \\
\hline
\end{tabular}

${ }^{\mathrm{a}}$ Retention time; ${ }^{\mathrm{b}}$ abundance: \% area.

\subsection{Antiparasitic Effects}

The antiparasitic activity of the essential oils, their major compounds (camphor and 1,8-cineole), and their 1:1 combination are shown in Table 2. Among the essential oils, the one from the aeroponic population (AasA) was more active than the oil from the greenhouse plants against both parasites. The T. cruzi epimastigotes were more sensible to the effect of these EOs than the P. davidi promastigotes. The fact that $P$. davidi is a plant parasite could explain this selective effect. On the other hand, none of the major compounds (1,8-cineole and camphor) in their 1:1 mixture showed an antiparasitic activity. Similarly, none of the essential oils or the pure compounds tested showed an inhibition of the FP biocrystallization in the FBIT test (Table S1 in Supplementary Material).

Table 2. Activity on Trypanosoma cruzi epimastigotes and Phytomonas davidi promastigotes of Artemisia pedemontana subsp. assoana EOs, their major components 1,8-cineole and camphor, and a 1:1 mixture of each compound.

\begin{tabular}{cccc}
\hline EO/Compound & Concentration $(\mu \mathrm{g} / \mathbf{m L})$ & T. $_{\text {cruzi }}{ }^{\text {a }}$ & P. davidi $^{\text {a }}$ \\
\hline \multirow{2}{*}{ AasG EO } & 800 & $100 \mathrm{a}$ & 100 \\
& 400 & $100 \mathrm{a}$ & 0.0 \\
& 200 & $20.3 \pm 4.6 \mathrm{~b}$ & 0.0 \\
\hline \multirow{2}{*}{ AasA EO } & 800 & $99.4 \pm 0.6 \mathrm{a}$ & $100 \mathrm{a}$ \\
& 400 & $100 \mathrm{a}$ & $72.7 \pm 12.9 \mathrm{~b}$ \\
& 200 & $72.1 \pm 3.2 \mathrm{~b}$ & 0.0 \\
1,8-Cineole & 100 & $14.6 \pm 2.9 \mathrm{c}$ & - \\
\hline Camphor & 100 & $2.0 \pm 2.5$ & 0.0 \\
\hline Cineole:Camphor $1: 1$ & 10 & 0.0 & 0.0 \\
\hline
\end{tabular}

\footnotetext{
a Data are expressed as \% of growth inhibition (mean of three replicates \pm standard error, relative to untreated controls). Values within the same column followed by a different letter are significantly different; one-way analysis of variance (ANOVA) with least significant difference test $(p<0.05)$ were used for the analysis.
}

Artemisia sp. essential oils have been reported as being trypanocidal [14], specifically, essential oil from cultivated A. absinthium [5,7]. However, this is the first report on the trypanocidal activity of $A$. pedemontana subsp. assoana essential oil. A recent study reported 1,8-cineole as being inactive against T. cruzi, while compounds such as $p$-cymene, linalool, $\beta$-pinene, and $\gamma$-terpinene had strong effects [6]. Moreover, binary combinations of these compounds showed synergistic effects [6]. These compounds are also present in A. pedemontana subsp. assoana essential oils in different concentrations, and could explain the antiparasitic effects described here.

Several species of Phytomonas have been reported as being responsible of plant diseases in crops of economic importance, such as coffee and palm trees [20], with the removal of the infected plants being the only control available. Synthetic compounds such as triazolo-pyrimidine complexes have been reported as being active against Phytomonas sp. [27-29], and the natural alkaloids tomatine and 
tomatidine against P. serpens [30]. However, this is the first report of the activity of essential oils against promastigotes of Phytomonas sp.

\subsection{Insect Antifeedant and Biocidal Effects}

We tested the effects of the essential oils from A. pedemontana subsp. assoana against herbivorous insects, plants, nematodes, and fungi, to have an overall idea of the plant defensive properties allocated to its $\mathrm{EO}$, in addition to identifying the effects of their potential use in plant protection.

Table 3 shows the insect antifeedant effects of $A$. pedemontana subsp. assoana EOs, their major components 1,8-cineole and camphor, and a mixture (1:1) of both. The EO from the greenhouse population (AasG) was antifeedant to $S$. littoralis at the highest concentration tested, and showed moderate-low activity against the aphid $R$. padi. The aeroponic plant (AasA) EO was a moderate antifeedant to M. persicae and R. padi. The different antifeedant effects observed for A. pedemontana subsp. assoana EOs could be related to the quantitative and qualitative differences found in their chemical composition. Furthermore, the major EO components tested (1,8-cineole and camphor) did not show significant antifeedant effects alone or in a 1:1 mixture. These results indicate that the insect antifeedant activity could be modulated by the minor compounds of the EO.

Table 3. Insect antifeedant effects of Artemisia pedemontana subsp. assoana essential oils from greenhouse (AasG) and aeroponic plants (AasA); their major components, 1,8-cineole and camphor; and a 1:1 mixture of both compounds.

\begin{tabular}{ccccc}
\hline \multirow{2}{*}{ EO/Compound } & $\begin{array}{c}\text { Concentration } \\
\left(\mu \mathrm{g} / \mathbf{c m}^{\mathbf{2}}\right)\end{array}$ & S. littoralis & M. persicae & R. padi \\
\cline { 3 - 5 } & 100 & $\mathbf{\% F I}^{\mathbf{a}}$ & $\mathbf{\% S I}^{\mathbf{b}}$ & $\mathbf{\% S I}^{\mathbf{b}}$ \\
\hline AasG EO & 50 & $43.6 \pm 7.9 *$ & $46.1 \pm 8.9$ & $56.9 \pm 8.1^{*}$ \\
& 100 & $53.0 \pm 8.9$ & $76.1 \pm 7.2^{*}$ & $60.3 \pm 7.2^{*}$ \\
AasA EO & 50 & - & $29.7 \pm 7.6$ & - \\
\hline 1,8-Cineole & 50 & $12.3 \pm 7.6$ & $42.1 \pm 8.8$ & $35.8 \pm 7.4$ \\
Camphor & 50 & $59.9 \pm 12.6$ & $32.3 \pm 7.5$ & $33.2 \pm 7.8$ \\
Cineole:Camphor 1:1 & 50 & $62.7 \pm 11.2$ & $55.6 \pm 8.4$ & $40.4 \pm 7.8$ \\
\hline
\end{tabular}

a Percent feeding (\%FI) inhibition. Values are means of 10 replicates \pm standard error, ${ }^{b}$ Percent settling (\%SI) inhibition. Values are means of 20 replicates \pm standard error, ${ }^{*} p<0.05$, Wilcoxon signed-rank test.

The EOs $(0.4 \mu \mathrm{g} / \mu \mathrm{L})$ and their major components $(0.2 \mu \mathrm{g} / \mu \mathrm{L})$ were tested for their phytotoxicity against Lolium perenne and Lactuca sativa (monocotiledoneous and dicotiledoneous plants). Neither the EOs or their major components inhibited the germination of these plants at the end of the experiment (data not shown). The AasG EO inhibited the root and leaf growth of L. perenne (30\% growth inhibition respect to the control), and stimulated the growth of L. sativa root (53\% growth stimulation respect to the control.

The compound 1,8-cineole have reported phytotoxic effects against different plant species, including the moncot Echinocloa crusgalli and the dicot Cassia obtusifolia weeds, with the greatest effect on the monocot [31]; inhibited seed germination and seedling growth of L. sativa [32]; and inhibited the primary root growth of radish, Raphanus sativus [33]. This compound also inhibited all of the stages of mitosis in onion cells [32]. Camphor was phytotoxic against rice seedlings [34], and inhibited the seed germination and seedling growth of L. sativa [32] and the germination of radish [33]. Among the minor components of $A$. assoana EO, p-cymene was slightly active on L. sativa [32], and inhibited the root elongation of Lepidium sativum [33], and borneol, terpinen-4-ol, and linalool strongly inhibited seed germination and seedling growth of L. sativa [32]. Camphor, terpinen-4-ol, borneol, and linalool were present in higher concentrations in AasG EO (Table 1), and therefore could explain the phytotoxic effect of this oil. 
When tested against $A$. niger spores, both EOs inhibited fungal germination at the maximum dose tested (Table 4 ), with the AasG EO being the most active (83\% inhibition). The compounds 1,8-cineole and camphor, and their 1:1 combination, were not active against $A$. niger germination (Table 4 ). Among the minor components of the EO, $p$-cymene, linalool, $\alpha$-pinene, $\alpha-, \gamma$-terpinene, and terpinen-4-ol have reported antifungal actions, including synergism between 1,8 cineole and linalool (only present in the most active oil AasG) [35]. Therefore, the minor components of these EOs could play an important role in their antifungal effects.

Table 4. Effects of Artemisia pedemontana subsp. assoana essential oils; their major compounds, 1,8-cineole and camphor; and a 1:1 mixture of both compounds on Aspergillus niger spore germination.

\begin{tabular}{ccc}
\hline EO/Compound & Concentration $(\mu \mathrm{g} / \mathbf{m L})$ & $\mathbf{\% ~ I ~}^{\mathbf{a}}$ \\
\hline & 800 & $83.7 \pm 2.3 \mathrm{a}$ \\
AasG EO & 400 & $39.06 \pm 6.3 \mathrm{~b}$ \\
& 200 & $33.9 \pm 11.6 \mathrm{~b}$ \\
\hline & 800 & $67.8 \pm 6.3 \mathrm{a}$ \\
AasA EO & 400 & $38.6 \pm 13.4 \mathrm{~b}$ \\
& 200 & $16.1 \pm 4.3 \mathrm{c}$ \\
\hline 1,8-Cineole & 100 & 0.0 \\
\hline Camphor & 100 & $24.2 \pm 9.8$ \\
\hline Cineole:Camphor 1:1 & 100 & $26.7 \pm 8.0$
\end{tabular}

a Percent spore germination inhibition (I). Values within the same column followed by different letter are significantly different; one-way ANOVA with least significant difference (LSD) test $(p<0.05)$ were used for the analysis.

A. pedemontana subsp. assoana essential oils were not nematicidal, while the hydrolate resulted in a high mortality of J2 M. javanica (Table 5), which indicates that active components were present in the water fraction. The nematicidal activity of the hydrolate was further tested on the egg hatchability inhibition without any positive result (Table S2 in Supplementary Material), confirming that egg masses are less sensitive to the effects of extracts than J2 [11].

Table 5. Effects of Artemisia pedemontana subsp. assoana essential oils (EO) at $1 \mathrm{mg} / \mathrm{mL}$ and hydrolate (H) on mortality of M. javanica second stage juveniles (J2).

\begin{tabular}{|c|c|c|}
\hline $\mathrm{EO} / \mathrm{H}$ & J2 mortality (\%) a & LC50 ${ }^{b}$ \\
\hline AasG EO & $3.72 \pm 0.23 a$ & - \\
\hline AasA EO & $3.06 \pm 0.35 a$ & - \\
\hline AasA H & $96.4 \pm 1.1 b$ & $74(70-80)$ \\
\hline
\end{tabular}

a Values are means of four replicates \pm standard deviation, corrected according to Scheider-Orelli's formula). Values within the same column followed by different letter are significantly different; one-way ANOVA with least significant difference (LSD) test $(p<0.05)$ were used for the analysis. ${ }^{\mathrm{b}}$ Five serial dilutions were used to obtain $\mathrm{LC}_{50}(95 \%$ confidence limits).

In vivo tests on tomato seedlings resulted in a strong suppression of the $\mathrm{J} 2$ root penetration when treated with the hydrolate at a sublethal dose $\left(\mathrm{LD}_{50}\right.$; Table 5). The experiment was repeated twice, showing a significant decrease of $\mathrm{J} 2$ root penetration (34\% and $26 \%$ ) with respect to the control (inoculated with untreated J2; Figure 2). Therefore, the hydrolate affected the nematode behavior by suppressing juvenile penetration in the roots and reducing the nematode infection of tomato plants.

Hydrolates are distillation byproducts, and contain volatile compounds with a high polarity that remain dissolved in water and do not occur in the essential oil [36]. Similar nematicidal effects have been reported for hydrolates from the distillation of A. absinthium var. Candial [11], Lavandula $x$ intermedia var. super [37], L. luisieri [25,37], and two species of Thymus [37] against M. javanica. However, further research is needed in order to characterize the nematicidal components present in the active hydrolate of $A$. pedemontana subsp. assoana. 


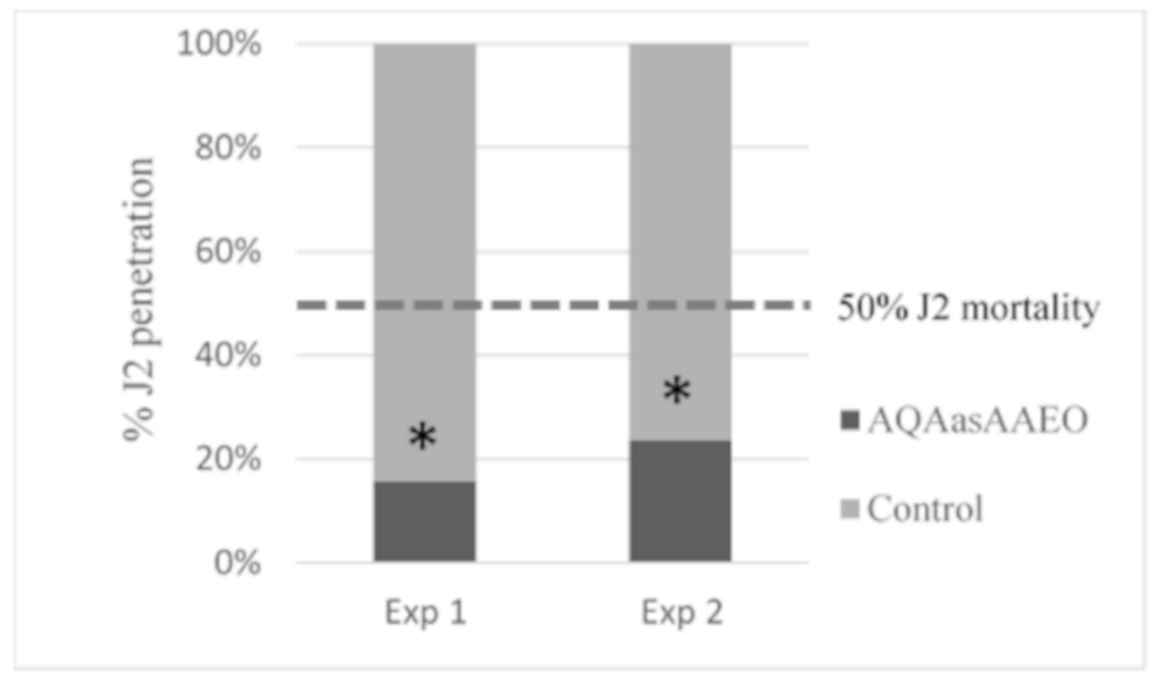

Figure 2. Effects of Artemisia pedemontana subsp. assoana hydrolate at a sublethal concentration (74\%) on Meloydogine javanica juvenile infection capacity of Solanum lycopersicum root seedlings (two experiments). Bars represent the penetration percentage of treated J2 (hydrolate) vs. untreated J2 (control). * Denotes a statistically significant difference (Chi-square test) between the proportion of control juveniles (untreated) and treated juveniles that penetrated the tomato roots.

\section{Conclusions}

In summary, A. pedemontana subsp. assoana has been successfully cultivated in the greenhouse and in aeroponic cultivation. The EOs from greenhouse- and aeroponically-cultivated plants showed a 1,8-cineol and camphor chemotype with quantitative and qualitative chemical differences. These essential oils were trypanocidal, and showed moderate phytomonacidal effects. The EOs also had moderate insect antifeedant and antifungal effects, while the hydrolate was a strong nematicidal.

Both EOs were similarly antifeedant, while the EO from the greenhouse plants (flowering stage) was more biocidal (antifungal, nematicidal, and phytotoxic) than the EO from the aeroponic plants (growing stage), which was more antiparasitic. The major components of the oils (1,8-cineole and camphor) or their 1:1 combination did not explain any of these effects. We can conclude that these EOs have potential applications as insect antifeedants, and antifungal or antiparasitic agents, depending on the cultivation method, and if the hydrolate byproduct is a potent nematicidal.

Supplementary Materials: The following are available online at http://www.mdpi.com/2218-273X/9/10/558/s1, Table S1: Activity on FBIT test of A. assoana EOs, Table S2: Egg hatching inhibition effects of AasA hydrolate on Meloidogyne javanica.

Author Contributions: Conceptualization, R.A.M.-D., C.E.D., M.F.A., and A.G.-C.; formal analysis, A.G.-C; funding acquisition, C.E.D., M.F.A., and A.G.-C.; investigation, P.S., R.A.M.-D., M.B., J.N.-R., C.E.D., M.F.A., and A.G.-C.; methodology, P.S., R.A.M.-D., M.B., J.N.-R., M.F.A., and A.G.-C.; project administration, C.E.D., M.F.A., and A.G.-C.; resources, A.G.-C.; supervision, R.A.M.-D., C.E.D., M.F.A., and A.G.-C.; validation, P.S., M.B., and J.N.-R.; writing (original draft), P.S.; writing (review and editing), R.A.M.-D., C.E.D., M.F.A., and A.G.-C.

Funding: This research was funded by MINECO/FEDER grant CTQ2015-64049-C3-1-R. P. Sainz was funded by a MINECO FPI predoctoral grant.

Conflicts of Interest: The authors declare no conflict of interest.

\section{References}

1. Abad, M.J.; Bedoya, L.M.; Apaza, L.; Bermejo, P. The Artemisia L. genus: A review of bioactive essential oils. Molecules 2012, 17, 2542-2566. [CrossRef] [PubMed] 
2. Huang, J.; Qian, C.; Xu, H.; Huang, Y. Antibacterial activity of Artemisia asiatica essential oil against some common respiratory infection causing bacterial strains and its mechanism of action in Haemophilus influenzae. Microb. Pathog. 2018, 114, 470-475. [CrossRef] [PubMed]

3. Pandey, B.; Thapa, R.; Upreti, A. Chemical composition, antioxidant and antibacterial activities of essential oil and methanol extract of Artemisia vulgarias and Gaultheria fragantissima collected from Nepal. Asia Pac. J. Trop. Med. 2017, 10, 952-959. [CrossRef] [PubMed]

4. Lu, M.; Han, Z.; Xu, Y.; Yao, L. In vitro and in vivo anti-tobacco mosaic virus activities of essential oils and individual compounds. J. Microbiol. Biotechnol. 2013, 23, 771-778. [CrossRef] [PubMed]

5. Bailén, M.; Julio, L.F.; Diaz, C.E.; Sanz, J.; Martínez-Díaz, R.A.; Cabrera, R.; Burillo, J.; Gonzalez-Coloma, A. Chemical composition and biological effects of essential oils from Artemisia absinthium L. cultivated under different environmental conditions. Ind. Crop Prod. 2013, 49, 102-107. [CrossRef]

6. Guardo, N.I.; Sainz, P.; González-Coloma, A.; Burillo, J.; Martínez-Díaz, R.A. Trypanocidal effects of essential oils from selected medicinal plants. Synergy among the main components. Nat. Prod. Commun. 2017, 12, 709-712. [CrossRef] [PubMed]

7. Martínez-Díaz, R.A.; Ibáñez-Escribano, A.; Burillo, J.; de las Heras, L.; del Prado, G.; Agulló-Ortuño, M.T.; Julio, L.F.; González-Coloma, A. Trypanocidal, trichomonacidal and cytotoxic components of cultivated Artemisia absinthium Linnaeus (Asteraceae) essential oil. Mem. I Oswaldo Cruz 2015, 110, 693-699. [CrossRef]

8. Ferreira, J.F.S.; Luthria, D.L.; Sasaki, T.; Heyerick, A. Flavonoids from Artemisia annua L. as antioxidant and their potential synergism with artemisinin against malaria and cancer. Molecules 2010, 15, 3135-3170. [CrossRef] [PubMed]

9. Ivanescu, B.; Miron, A.; Corciova, A. Sesquiterpene lactones from Artemisia genus: Biological activities and methods of analysis. J. Anal. Methods Chem. 2015, 247685. [CrossRef]

10. Julio, L.F.; González-Coloma, A.; Burillo, J.; Diaz, C.E.; Andrés, M.F. Nematicidal activity of the hydrolate byproduct from the semi industrial vapor pressure extraction of domesticated Artemisia absinthium against Meloidogyne javanica. Crop Prot. 2017, 94, 33-37. [CrossRef]

11. Julio, L.F.; Burillo, J.; Giménez, C.; Cabrera, R.; Díaz, C.E.; Sanz, J.; González-Coloma, A. Chemical and biocidal characterization of two cultivated Artemisia absinthium populations with different domestication levels. Ind. Crop Prod. 2015, 76, 787-792. [CrossRef]

12. González-Coloma, A.; Reina, M.; Díaz, C.E.; Fraga, B.M.; Santana-Meridas, O. Natural product-based biopesticides for insect control. In Elsevier Reference Module in Chemistry, Molecular Sciences and Chemical Engineering; Reedijk, J., Ed.; Elsevier: Waltham, MA, USA, 2013. [CrossRef]

13. Sainz, P.; Sanz, J.; Burillo, J.; González-Coloma, A.; Bailén, M.; Martínez-Díaz, R.A. Essential oils for the control of reduviid insects. Phytochem. Rev. 2012, 11, 361-369. [CrossRef]

14. Sainz, P.; Cruz-Estrada, A.; Díaz, C.E.; González-Coloma, A. The genus Artemisia: Distribution and phytochemistry in the Iberian Peninsula and the Canary and Balearic Islands. Phytochem. Rev. 2017, 16, 1-21. [CrossRef]

15. Greuter, W. Compositae (pro parte majore). In Compositae. Euro+Med Plantbase the Information Resource for Euro-Mediterranean Plant Diversity; Greuter, W., von Raab-Straube, E., Eds.; Università degli Studi di Palermo: Palermo, Italy, 2005; Available online: http://ww2.bgbm.org/EuroPlusMed (accessed on 15 September 2019).

16. Hassler, M. World Plants: Synonymic Checklists of the Vascular Plants of the World. In Species $2000 \mathcal{E}$ ITIS Catalogue of Life; Roskov, Y., Abucay, L., Orrell, T., Nicolson, D., Bailly, N., Kirk, P.M., Bourgoin, T., DeWalt, R.E., Decock, W., De Wever, A., et al., Eds.; Species 2000: Leiden, The Netherlands, 2017; ISSN 2405-8858. Available online: www.catalogueoflife.org/col (accessed on 15 September 2019).

17. Perez-Alonso, M.J.; Velasco-Negueruela, A.; Palá-Paúl, J.; Sanz, J. Variations in the essential oil composition of Artemisia pedemontana gathered in Spain: Chemotype camphor-1,8-cineole and chemotype davanone. Byochem. Syst. Ecol. 2003, 31,77-84. [CrossRef]

18. Marco, J.A.; Barbera, O.; Martinez, V.; Strack, D.; Meurer, B. Sesquiterpene Lactones from Artemisia assoana. Planta Med. 1988, 54, 460-461. [CrossRef] [PubMed]

19. Martínez, V.; Barbera, O.; Sánchez-Parareda, J.; Marco, J.A. Phenolic and acetylenic metabolites from Artemisia assoana. Phytochemistry 1987, 26, 2619-2624. [CrossRef]

20. Jaskowska, E.; Butler, C.; Preston, G.; Kelly, S. Phytomonas: Trypanosomatids Adapted to Plant Environments. PLoS Pathog. 2015, 11, 1-17. [CrossRef] 
21. Bourdy, G.; Oporto, P.; Gimenez, A.; Deharo, E. A search for natural bioactive compounds in Bolivia through a multidisciplinary approach Part VI. Evaluation of the antimalarial activity of plants used by Isoceño-Guaraní Indians. J. Ethnopharmacol. 2004, 93, 269-277. [CrossRef]

22. Deharo, E.; Garcia, R.; Oporto, P.; Sauvain, M.; Gautret, P.H.; Ginsburg, H. A non-radiolabeled ferriprotoporphyrin IX bomineralization inhibition test (FBIT) for the high throughput screening of antimalarial compounds. Exp. Parasitol. 2002, 100, 252-256. [CrossRef]

23. Poitout, S.; Bues, S. Elevage de plusieursespeces de Lepidopteres Noctuidae sur milleu artificiel simplifié. Ann. Zool. Ecol. Anim. 1970, 2, 79-91.

24. Santana, O.; Andres, M.F.; Sanz, J.; Errahmani, N.; Abdeslam, L.; Gonzalez-Coloma, A. Valorization of essential oils from Moroccan aromatic plants. Nat. Prod. Commun. 2014, 9, 1109-1114. [CrossRef] [PubMed]

25. Julio, L.F.; Barrero, A.F.; Herrador del Pino, M.M.; Arteaga, J.F.; Burrillo, J.; Andrés, M.F.; Díaz, C.E.; González-Coloma, A. Phytotoxic and nematicidal components of Lavandula luisieri. J. Nat. Prod. 2016, 79, 261-266. [CrossRef] [PubMed]

26. Clausen, C.A.; Yang, V.W. Colorimetric micro-assay for accelerated screening of mould inhibitors. Int. Biodeterior. Biodegrad. 2013, 77, 68-71. [CrossRef]

27. Luque, F.; Fernández-Ramos, C.; Entrala, E.; Rosales, M.J.; Salas, C.M.; Navarro, J.A.; Sánchez-Moreno, M. Biochemical and ultrastructutral alterations caused by newly synthesized 1,2,4-triazole [1,5a] pyrimidine derivates against Phytomonas staheli (Trypanosomatidae). Toxicol. In Vitro 2000, 14, 487-495. [CrossRef]

28. Magán, R.; Marín, C.; Salas, J.M.; Barrera-Pérez, M.; Rosales, M.J.; Sánches-Moreno, M. Cytotoxicity of three new triaxolo-pyrimidine derivates against the plant trypanosomatid: Phytomonas sp. Isolated from Euphorbia characias. Mem. I. Oswaldo Cruz 2004, 99, 651-656. [CrossRef]

29. Salas, J.M.; Quirós, M.; Haj, M.A.; Magán, R.; Marín, C.; Sánchez-Moreno, M.; Faure, R. Activity of Pt(II) and $\mathrm{Ru}(\mathrm{III})$ triazolopyrimidine complexes against parasites of the genus Leishmania, Trypanosoma and Phytomonas. Met.-Based Drugs 2001, 8, 119-124. [CrossRef] [PubMed]

30. Medina, J.M.; Fernandes, J.C.; Moreira, O.C.; Atella, G.; de Souza, W.; Barrabin, H. Mechanisms of growth inhibition of Phytomonas serpens by the alkaloids tomatine and tomatidine. Mem. I Oswaldo Cruz 2015, 110, 48-55. [CrossRef]

31. Romagni, J.G.; Allen, S.N.; Dayan, F.E. Allelopathic effects of volatile cineoles on two weedy plant species. J. Chem. Ecol. 2000, 26, 303-3013. [CrossRef]

32. Vokou, D.; Douvli, P.; Blionis, G.; Halley, J. Effects of monoterpenoids, acting alone or in pairs, on seed germination and subsequent seedling growth. J. Chem. Ecol. 2003, 29, 2281-2301. [CrossRef]

33. De Martino, L.; Mancini, E.; Almeida, L.F.R.; De Feo, V. The antigerminative activity of twenty-seven monoterpenes. Molecules 2010, 15, 6630-6637. [CrossRef]

34. Okamoto, Y.; Yamaji, K.; Kobayashi, K. Allelopathic activity of camphor released from camphor tree (Cinnamomum camphora). ACS Symp. Ser. 2011, 27, 123-132.

35. Tariq, S.; Wani, S.; Rasool, W.; Shafi, K.; Bhat, M.A.; Prabhakar, A.; Shalla, A.H.; Rather, M.A. A comprehensive review of the antibacterial, antifungal and antiviral potential of essential oils and their chemical constituents against drug-resistant microbial pathogens. Microb. Pathog. 2019, 134, 103580. [CrossRef] [PubMed]

36. Wajs-Bonikowska, A.; Sienkiewicz, M.; Stobiecka, A.; Maciag, A.; Szoka, L.; Karna, E. Chemical composition and biological activity of Abies alba and A. koreana seed and cone essential oils and characterization of their seed hydrolates. Chem. Biodivers. 2015, 12, 407-418. [CrossRef] [PubMed]

37. Andrés, M.F.; González-Coloma, A.; Muñoz, R.; De la Peña, F.; Julio, L.F.; Burillo, J. Nematicidal potential of hydrolates from the semi industrial vapor-pressure extraction of Spanish aromatic plants. Environ. Sci. Pollut. Res. Int. 2017. [CrossRef] [PubMed]

(C) 2019 by the authors. Licensee MDPI, Basel, Switzerland. This article is an open access article distributed under the terms and conditions of the Creative Commons Attribution (CC BY) license (http://creativecommons.org/licenses/by/4.0/). 